\title{
A Study on Moyna Basin Water-Logged Areas (India) Using Remote Sensing and GIS Methods and Their Contemporary Economic Significance
}

\author{
Abhay Sankar Sahu \\ Department of Geography, University of Kalyani, West Bengal, Nadia 741235, India \\ Correspondence should be addressed to Abhay Sankar Sahu; sahu.abhaysankar@gmail.com
}

Received 15 January 2014; Revised 11 April 2014; Accepted 17 April 2014; Published 18 May 2014

Academic Editor: Huayu Lu

Copyright (C) 2014 Abhay Sankar Sahu. This is an open access article distributed under the Creative Commons Attribution License, which permits unrestricted use, distribution, and reproduction in any medium, provided the original work is properly cited.

\begin{abstract}
The prime objective of this paper is to identify and map the water-logged areas within Moyna basin, India, and to explore their contemporary economic significances. The Landsat 5 TM, ASTER data, and topographical sheets have been taken into consideration with field observations. Maps on relief, slope, canal density, embankments, a supervised classification of the study area and then NDVI, NDWI, and modified NDWI or NDMI have been prepared here. At Moyna, the piezometric surface ranges from five to ten metres below the ground level. The percentage of clay particles is high throughout the surface soil. The total rainfall is nearly $1400 \mathrm{~mm}$ and most of it happened during the monsoon period. Two well-marked depressions are observed there within the basin and the nearly central one is wide and is clearly identified from the relief map also. Problem of drainage congestion there accelerates the onset of water-logged situation. In general, water-logged areas are not suitable for humans. People once were worried about the water-logged environment due to underwater scenario of low-lying agricultural fields for a certain period, but today local people are taking this environmental condition as an opportunity for fishing activity and thus they are becoming economically benefitted as well.
\end{abstract}

\section{Introduction}

Water-logged condition is a quasinatural manifestation of lowlands and these are important in the study of man and environment. Water-logged areas, an environmental problem [1], are observed throughout the world over China, Pakistan, Bangladesh, India, and so forth, and therefore this problem of water-logging is regarded as a global issue [2]. Within the wide range of environmental issues, it is a hydromorphological occurrence which needs spatial encounter towards economic management as well as development of an area. Normally water-logged environment encompasses flood basins with drainage problem.

Water-logged environment is found in the areas where soil remains saturated with water [3]. The word "waterlogged" is used as an adjective referring to soil that is saturated with water and thus cannot keep oxygen between its particles [4]. The water-logged condition is a result of blockage of water on the land surface, especially in a low-lying area. This blocking of water is controlled by local geology, topography, drainage, and the amount of water supplied to the site [5]. It is also the result of changing landuse within the human environment. Sometimes the water-logged situation of an area is the outcome of all-round embanking with poor drainage system; Moyna basin is a classic example of this type of blocking [6]. Water-logging happens due to unscientific management of water and obstruction of natural drainage systems by the haphazard embankment construction through disrupting the balance of inflow and outflow of water. Waterlogging like flooding causes damage to agricultural lands affecting the crops and thus the livelihood and the economy of the country [7]. Sometimes, excessive rainfall within a very short span of time creates water-logged situation in both the rural and urban areas. In India, water-logging problem 
is one of the main reasons for land degradation [8]. Thus, different factors like geological structure, excessive rainfall, drainage congestion, dense haphazard embankments, cyclones, flooding, river basin encroachment through siltation, and finally human activities have resulted into waterlogged situation. Furthermore, water-logging may be caused due to overirrigation. Water-logging is also regarded as the consequence of rising water table within the subsurface soil. It is the consequence of all round intra- and interrelationship of climatic, geomorphic, hydrologic, vegetative, and anthropogenic factors in our planetary environment. In the coastal areas of Bangladesh sea level rising leads to the onset of water-logged environment [9]. Water-logging often occurs in summer at the north of the Yellow river of the North China plain [10] and it is a serious problem in Bangladesh along with coastal flooding [9]. Water-logging is found in Pakistan due to construction of a large number of unlined canals in the Indus Basin System [11]. Thus, there are natural, quasinatural, and man-made factors behind the onset of water-logging hazards. Some of the water-logging scenarios are permanent and others are manifested as seasonal. Thus water-logging is time and place specific as well. Water-logged areas are not wetlands, but sometimes they are manifested as wetlands. When the incidence like water-logging is created it can be observed as well as studied from the environment perspective. Now, the question is that how are water-logged areas identified? Then, nowadays, is water-logging condition of a region a problem or helpful or not much remarkable for the region's economic development? It is also a task to know the opinions of the local people on this phenomenon in the problem areas.

Therefore, the prime objective of this paper is to identify and map the water-logged areas within Moyna basin and to explore their contemporary economic significances.

\section{Study Area}

Moyna basin (Figure 1) on the north-west part of the district of Purba Medinipur in the state of West Bengal in India has been selected for empirical observations. It is extended from $22^{\circ} 09^{\prime} 37^{\prime \prime} \mathrm{N}$ to $22^{\circ} 18^{\prime} 58^{\prime \prime} \mathrm{N}$ latitude and $87^{\circ} 42^{\prime} 17^{\prime \prime} \mathrm{E}$ to $87^{\circ} 49^{\prime} 53^{\prime \prime} \mathrm{E}$ longitude. Moyna is bounded by the rivers Kasai and Chandia from the east and west, respectively. River Chandia and Keleghai are on the south and the Baksi canal is on the north. The total geographical area of the Moyna basin is about $131 \mathrm{~km}^{2}$.

Moyna block is a remnant of paleo-coast and it is treated under Kasai plain [12]. In the historic past, Moyna was a Mohana region, that is, a place where different water-bodies meet and fall into the ocean. Lithologically, Moyna basin is characterised by recent alluvium of the Quaternary to upper Tertiary period. There is Holocene alluvial lowland, a physiographic division of the Bengal basin of the GangaBrahmaputra-Meghna system [13]. Moyna block, a drainage basin, looks like a trough [14]. The physical setup of Moyna is characterised by uneven geomorphological changes particularly in the fields of siltation, soil formation, structure of lands, and drainage system [6].

\section{Materials and Methods}

It is the systematic analysis of the water-logged areas to understand the linkages between man and environment from the spatial as well as environmental perspective. Figure 2 shows a flow chart to understand the methods and materials used here to fulfil our objective. Here the US Geological Survey (USGS) Landsat 5 Thermal Mapper (TM) data (2009), the USGS Global Visualisation Viewer (GLOVIS) Advanced Spaceborne Thermal Emission and Reflection (ASTER) data (2009), and topographical sheets $73 \mathrm{~N} / 11,73 \mathrm{~N} / 12,73 \mathrm{~N} / 15$, and 73N/16 (scale: 1:50,000; year: 1970) have been used for this study. From the topographical sheets, processing through Arc GIS 9.3 software, considering spot elevations haphazardly spreading all over the study area and its surroundings, a relief map representing elevation variations and contour lines within the study area; a slope map to depict the slope variations; a canal density map; and a map for embankments distribution have been prepared. Again, another relief map has also been prepared from the GLOVIS ASTER data which automatically creates DEM with the help of Arc GIS 9.3 software. Then, from the Landsat 5 TM imagery of the dated of December 11, 2009, with the help of Arc GIS 9.3 and ERDAS Imagine 9.1 software, after bandwise conversion of the quantised and calibrated scaled digital number (DN), known as DN value of the bands, to top of atmosphere (TOA) radiance value, a supervised classification of the study area has been made to crop out and then map the waterlogged areas. Then, with the help of Arc GIS 9.3, using certain formula of raster calculation for the TM bands, maps on the Normalized Difference Vegetation Index (NDVI), Normalized Difference Water Index (NDWI), and modified NDWI or Normalized Difference Moisture Index (NDMI) have been prepared. Above all, the study area has been surveyed for several times in rainy season and also after rainy season towards field checking.

\section{Results and Discussion}

4.1. Elevation and Slope. Positional water-logged situation depends on two topographic factors and these factors control the probability of water-logging where it increases with the contributing drainage area and decreases with increasing local slope angle [15]. Figure 3 shows the relief variations, contour lines, and slope characteristics of land surfaces within Moyna basin based on topographical maps and ASTER data. Mukhopadhyay [16] presented a detailed contour network of the Moyna basin. He highlighted the two depressions, one in the centre and the other in the southeast corner. From Figures 3(a) and 3(b) it is found that there are two depressions within the Moyna basin and the nearmiddle one is much larger as well as wide extended. Within Moyna basin relief varies from one to $15 \mathrm{~m}$ (Figure 3(a)). Maximum areas have elevation within three $\mathrm{m}$ (Figure 3(b)). From the outer riverine embankments toward centre the basin gets deep gradually; it is marked as negative slope for the purpose of water discharging from the basin. The central part is extended covering Balbhadrachak, Kripanandapur, Baitalchak, Kiarana, Kalagachia, Charandaschak, Uttar 


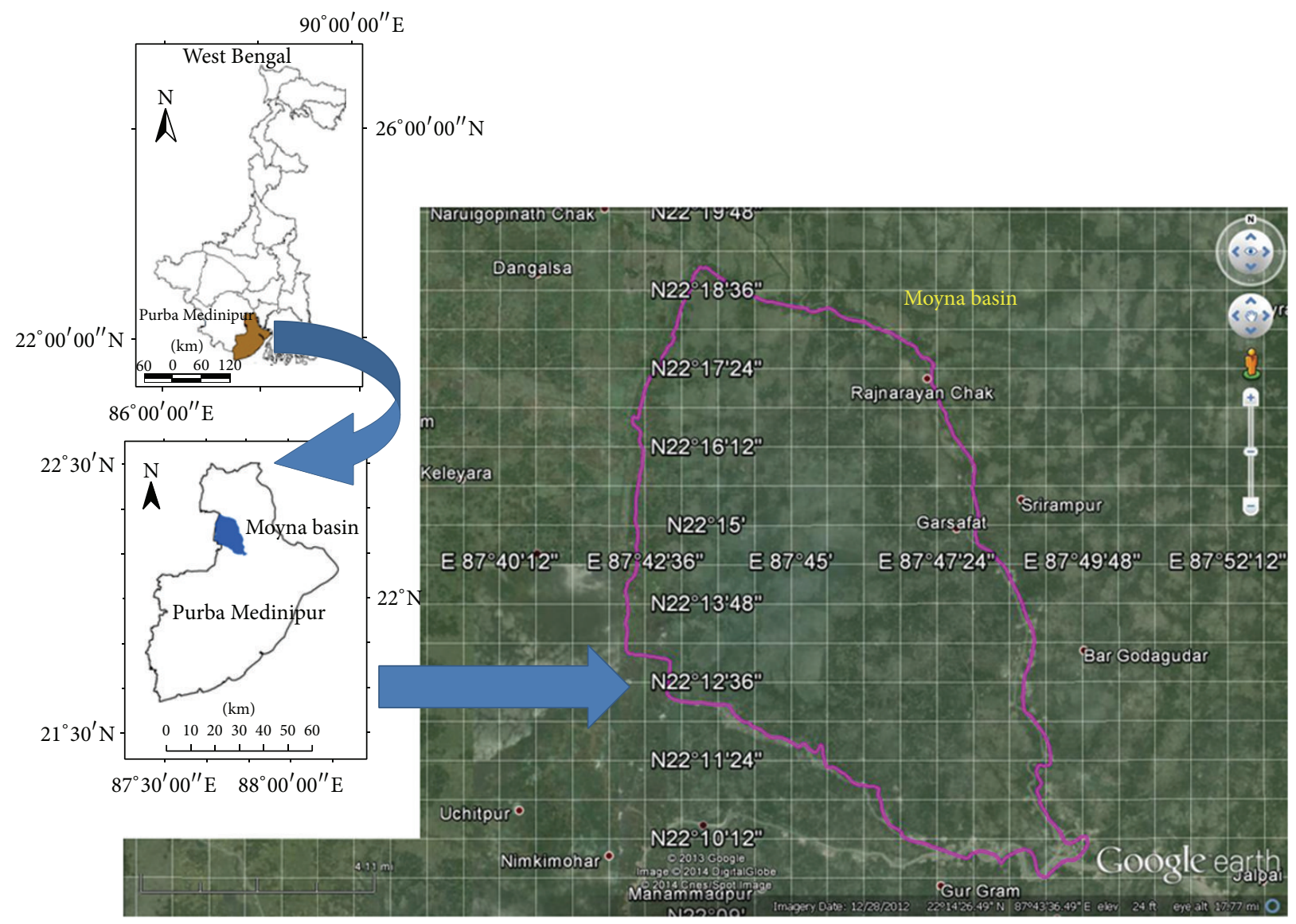

Figure 1: Study area.

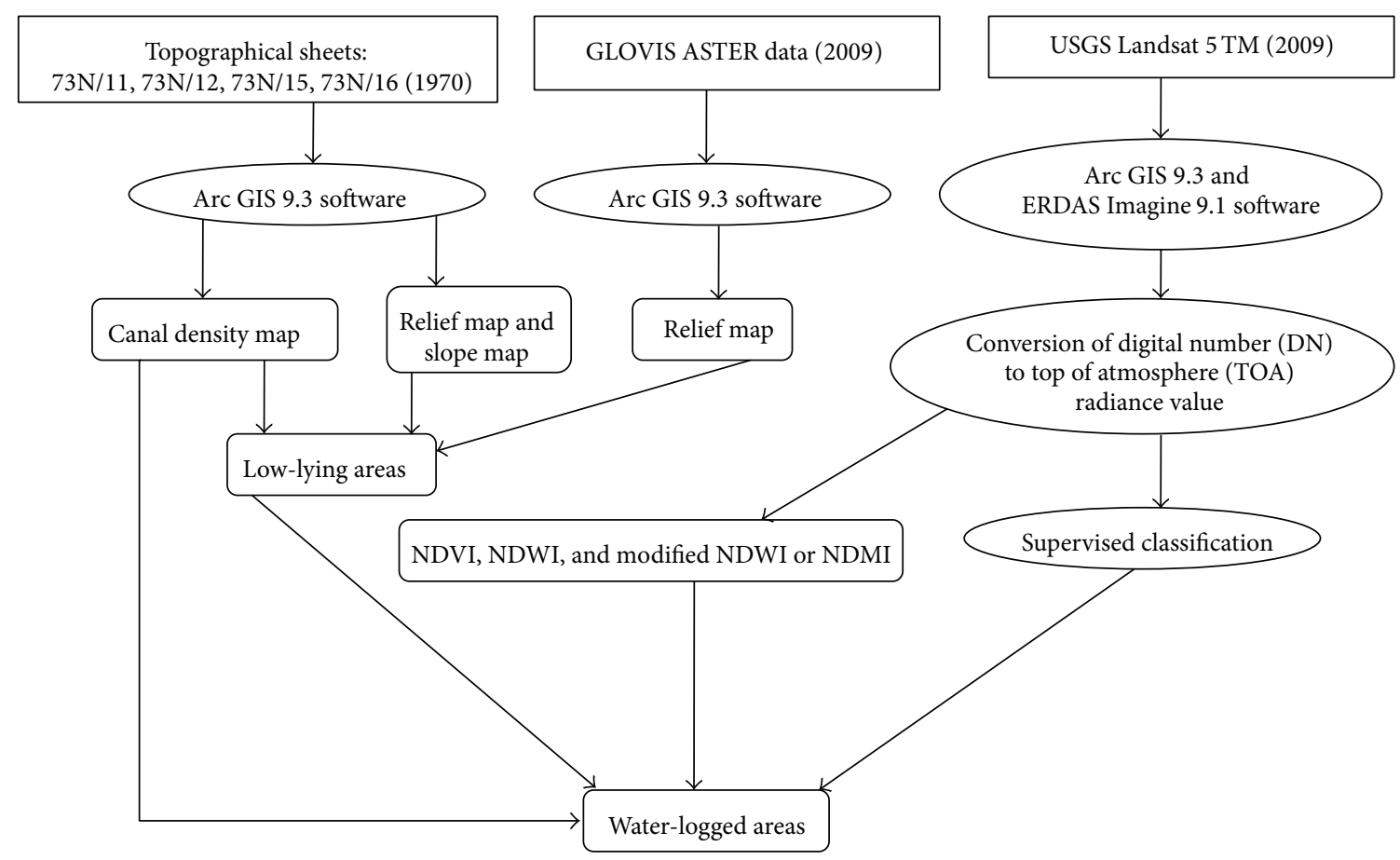

FIgURE 2: Methods and materials. 

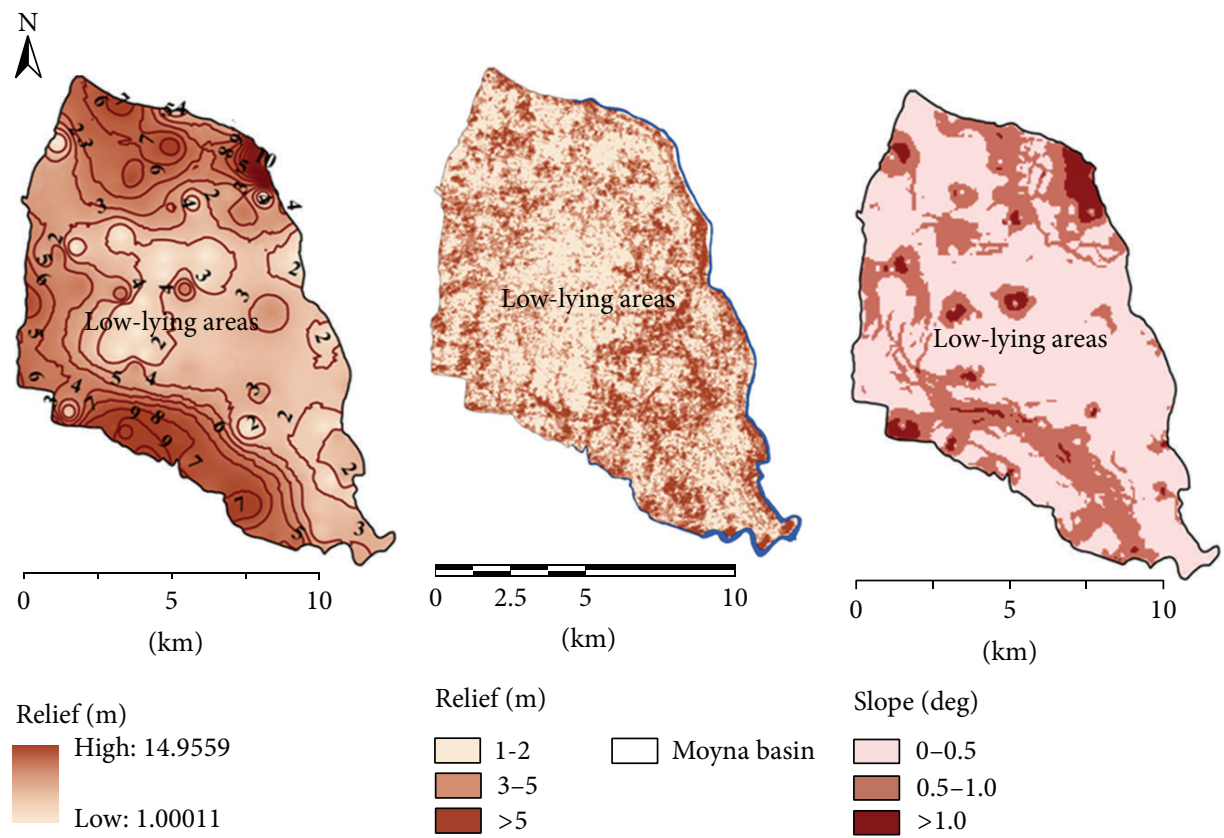

(a)

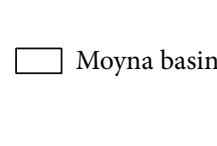

(b)
Slope (deg)

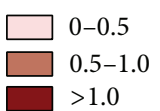

(c)

Figure 3: Surface characteristics of Moyna basin: (a) relief based on topographical sheets (73N/11, 73N/12, 73N/15, 73N/16: 1970); (b) relief based on GLOVIS ASTER Data (2009), projection system: UTM-WGS-1984; (c) slope based on topographical sheets (73N/11, 73N/12, 73N/15, 73N/16: 1970).

Anukha, and so forth, definitely over the low elevated areas, less than three m. Moderate elevated lands are found in the areas of Paramanandapur, Garmoyna, Deuli, Dakshin Harkuli, and so forth. Towards south of the Moyna basin, elevation is varying from five to ten $\mathrm{m}$. And, in other parts of the Moyna basin, elevation ranges from three $\mathrm{m}$ to five $\mathrm{m}$. From the ASTER data it is found that the slope is varying from zero to $0.98^{\circ}$ degrees . Figure 3 (c) depicts that the slope is $0.5^{\circ}$ for maximum areas and then $0.5^{\circ}$ to $1^{\circ}$ and lastly very negligible areas have more than $1^{\circ}$. It is a fact that in the areas where slope is very low and the areas are low-lying also than the surrounding areas the chance for creation of waterlogging is high as well.

4.2. Rainfall, Soil, and Ground Water. Extreme rainfall leads to water-logging of lands; the duration of water-logging changes in relation to the amount of rain, evapotranspiration, and soil structure [17]. Throughout the Purba Medinipur district, annual average rainfall is $1746.6 \mathrm{~mm}$. [18] and at Moyna, it is $1500 \mathrm{~mm}$. of which nearly 80 percentage occurred during the monsoon (June-September) period [19]. Water-logging influenced the soil properties of an area [20]. Sahu [21] presented particle distribution of soil of the Moyna basin where the clay (48.3 percentage) takes higher position remaining behind the silt (43 percentage) and the sand covered very negligible portion of 8.7 percentage. Higher percentage of clay indicates slower rate of vertical accretion under standing water. Disturbance in the hydrological balance finally leads to the water-logging [22]. Basack and Bhattacharya [23] mentioned that in the Purba Medinipur district water level below the ground surface ranges between three and 15 metres during premonsoon and in the postmonsoon period it is four to 12 metres. From the ground water table contouring, it is found that in the premonsoon and postmonsoon periods, at Moyna basin, ground water remains within four to seven metres depth. From the study in[24], it is observed that in the premonsoon period of 2007, at Moyna basin, piezometric surface was laid between five and ten metres below the ground level, particularly in the very negligible eastern parts, and it was between ten and 20 metres below the ground level on the western sides as well. Again, on a separate map, they showed that in the postmonsoon period of 2007, piezometric surface was laid between five and ten metres below the ground level throughout the Moyna basin.

4.3. Drainage and Embankments. In the nearly central position of the Moyna basin, the density of khals (canals) is high as shown in Figure 4(a). Drainage system of the Moyna basin presents the sewerage condition therein and maximum water drained throughout the study area by khals. During the rainy season, water is not clearly drained out from the basin due to negative slop towards the outer side of the Moyna basin. Therefore, water-logging is generated in the drainage congested areas.

At Moyna, various types of embankments are observed like high elevated river-front embankments (three to four $\mathrm{m}$ ), medium elevated canal-front embankments (two to $2.50 \mathrm{~m}$ ), and low elevated embankments (less than two $\mathrm{m}$ ) within the agricultural fields and fisheries. It is also observed that these embankments with different heights from the ground level 


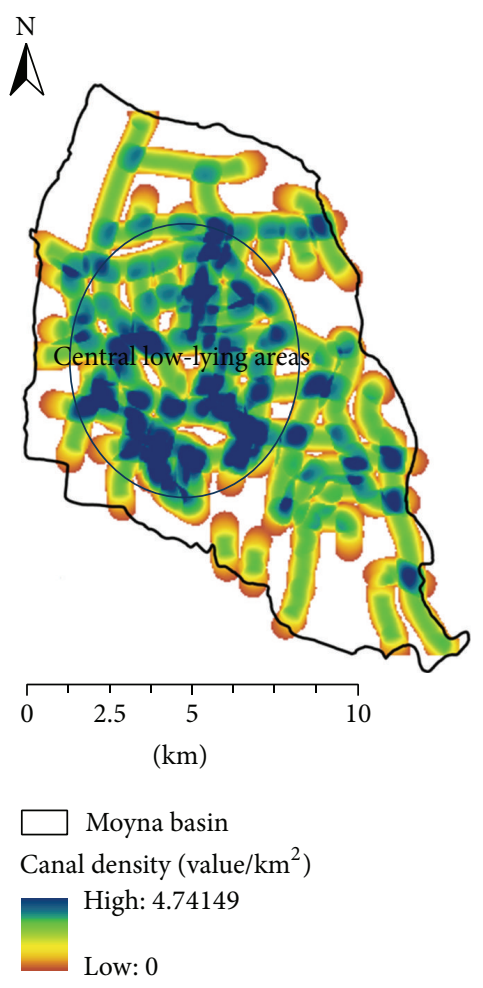

(a)

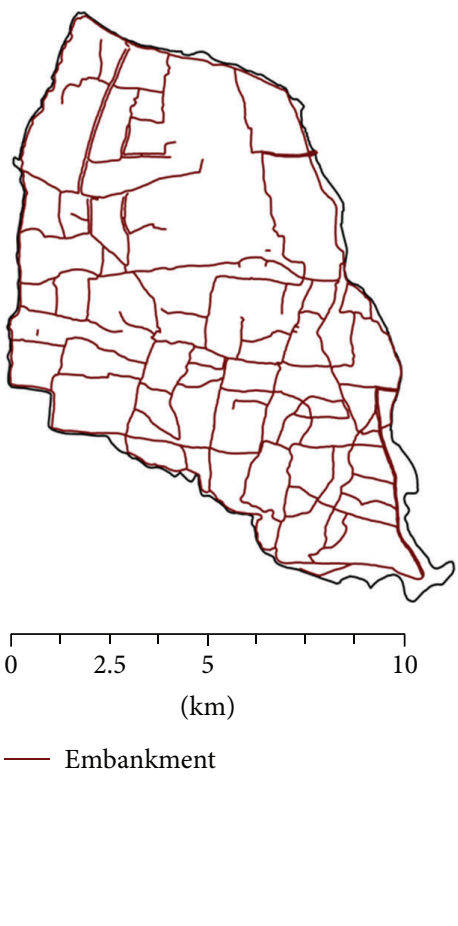

(b)

Figure 4: (a) Canal density and (b) embankments, based on topographical sheets (73N/11, 73N/12, 73N/15, 73N/16: 1970).

take a vital role to initiate water-logging condition through interrupting the natural surface-water flow, particularly in the areas where two or more embankments intersected with each other. Figure 4(b) shows the embankments net of the study area and that creates surface blocking of the monsoon rainwater. Thus, construction of the haphazard embankments is also a factor behind drainage congestion which leads to the onset of water-logging hazard.

4.4. Imagery Data Analysis. For a better understanding and visualising of the studied USGS Landsat 5 TM image dated back to December 11, 2009, it is important to convert the $\mathrm{DN}$ values to the TOA spectral radiance. The equation is as follows $[25,26]: L_{\lambda}=\left(\left(\operatorname{LMAX}_{\lambda}-\operatorname{LMIN}_{\lambda}\right) /(\mathrm{QCALMAX}-\right.$ QCALMIN) $) *(\mathrm{QCAL}-\mathrm{QCALMIN})+\mathrm{LMIN}_{\lambda}$, where $L_{\lambda}$ is spectral radiance (watt $/ \mathrm{m}^{2} *$ ster $* \mu \mathrm{m}$ ), QCAL is the quantised calibrated pixel value in $\mathrm{DN}, \operatorname{LMAX}_{\lambda}$ is the spectral radiance that is scaled to QCALMAX (watt $/ \mathrm{m}^{2} *$ ster $* \mu \mathrm{m}$ ),

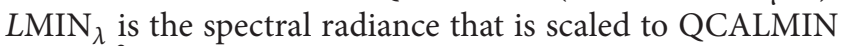
(watt $/ \mathrm{m}^{2} *$ ster $* \mu \mathrm{m}$ ), QCALMAX is the maximum quantised calibrated pixel value (corresponding to $L M A X_{\lambda}$ ) in $\mathrm{DN}$, and QCALMIN is the minimum quantised calibrated pixel value (corresponding to $L M I N N_{\lambda}$ ) in DN.

Now, after the atmospheric rectification of the image, a supervised classification of that has been prepared, which illustrates three major landuse features, just after completion of monsoon rainfall in the study area, with the help of Arc GIS 9.3 software (Figure 5). It shows that the water-logged areas are situated in the near middle zone, with a large extension, and haphazardly in other parts also. Here, it is observed that the total area under waterlogging in the Moyna basin is around $59 \mathrm{sq} . \mathrm{km}$. After a smooth field survey it has been observed that at Moyna, highly affected water-logged mouzas (villages) are Mathurichak, Harakhulibandarchak, Balbhadrachak, Kalagechia, Panch Pukuria, Gourangachak, Mathurapur, Baitalchak, Kripanandapur, Daksin Ankha, Uttar Ankha, Laluageria, Daksin Moyna, Charandaschak, and so forth. Low affected areas are Srikantha, Paramanandapur, Narkelda, Dakhin Chongrachak, Chongra, Chandiberia, Kiarana, and so forth. And other mouzas are medium-affected water-logged areas as well.

In support of this classification for water-logged areas (Figure 5), here NDVI, NDWI, and modified NDWI or NDMI have been prepared. The Normalized Difference Vegetation Index (NDVI) has been developed by Tucker [27] using red and near-infrared bands of the light. Here to calculate the NDVI, with the help of Arc GIS 9.3 software, the formula for the TM bands is as follows: NDVI = (Near-infrared [NIR], i.e., Band 4 - Red, i.e., Band 3)/(Near-infrared [NIR], i.e., Band $4+$ Red, i.e., Band 3). This method is found to be used to measure the vegetation cover and also the water bodies $[28,29]$. The NDVI value ranges from -1 to +1 [27]. Here, +1 denotes the dense vegetation and -1 signifies the presence of extensive deep water bodies. In the study area, the NDVI value ranges from +0.394737 to -0.387755 (Figure 6(a)). The 
areas of the lowest values, marked in Figure 6(a) within a circle, are same with the water-logged areas mentioned in Figure 5.

$\mathrm{Xu}$ [30] developed the Normalized Difference Water Index (NDWI) and it is used to delineate land from open water. The formula for NDWI, based on TM bands, applied through Arc GIS 9.3 software, is as follows: NDWI = (Green, i.e., Band 2 - Near-infrared [NIR], i.e., Band 4)/(Green, i.e., Band $2+$ Near-infrared [NIR], i.e., Band 4). NDWI shows the opposite result of NDVI. It ranges from -1 to +1 [30]. To understand the water-logged areas, NDWI values ranges from zero to +1 [31]. Chowdary et al. [31] made a study using NDWI values to search the water-logged areas in the state of Bihar, India. The upper limit, +1 , signifies the presence of extensive deep water bodies and the lower limit, -1 , denotes the vegetation covers. In Moyna basin, NDWI values range from +0.516129 to -0.184456 (Figure 6(b)). The areas of the highest values, marked in Figure 6(b) within a circle, are same with the already classified areas as water-logged in Figures 5 and $6(\mathrm{a})$.

The modified Normalized Difference Water Index (modified NDWI) is developed by Huang et al. [32] using nearinfrared (NIR) and changing the earlier green band of NDWI by middle-infrared (MIR) of the TM data. This method is used to identify soil moisture in a better way. It is also known as $\mathrm{NDWI}_{\mathrm{GAO}}$. For the Landsat 5 TM imagery, NIR is presented by band 4 and MIR by band 5 . The Normalized Difference Moisture Index (NDMI) is developed by Wilson and Sader [33] to investigate soil moisture using the

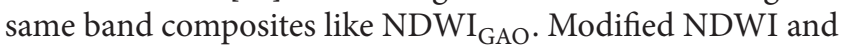
NDMI are theoretically similar to each other to detect spatial variations of surface wetness $[33,34]$. The formula for TM bands to calculate modified NDWI or $\mathrm{NDWI}_{\mathrm{GAO}}$ or NDMI is as follows: $\mathrm{NDWI}_{\mathrm{GAO}}$ or NDMI $=($ Near-infrared [NIR], i.e., Band 4 - Middle-infrared [MIR], i.e., Band 5)/(Nearinfrared [NIR], i.e., Band $4+$ Middle-infrared [MIR], i.e., Band 5). Here, the high NDMI value indicates the existence of much more soil moisture as well as water bodies and low value denotes the less existence of soil moisture. In the study area, modified NDWI or NDMI values ranges between +1 and +0.545455 (Figure 6(c)). This NDMI range indicates a good presence of soil moisture and that is found to truly happen when the area remained under prolonged waterlogged condition. The areas of the highest values, marked in Figure 6(c) within a circle, are same with the already classified areas as water-logged in Figure 5, and Figures 6(a) and $6(\mathrm{~b})$ as well. Thus, from the supervised classification of the image and maps using the methods of NDVI, NDWI, and modified NDWI or NDMI, water-logged areas can be assessed automatically.

\section{Contemporary Uses and Management}

Particularly in the critical periods, it is a priority that the use of water of a water-logged area meet people's basic needs and there water management shall comprise and induce multiple uses [35]. Managementmay be spatial, environmental, economic, socioeconomic, and so forth. Here, the word

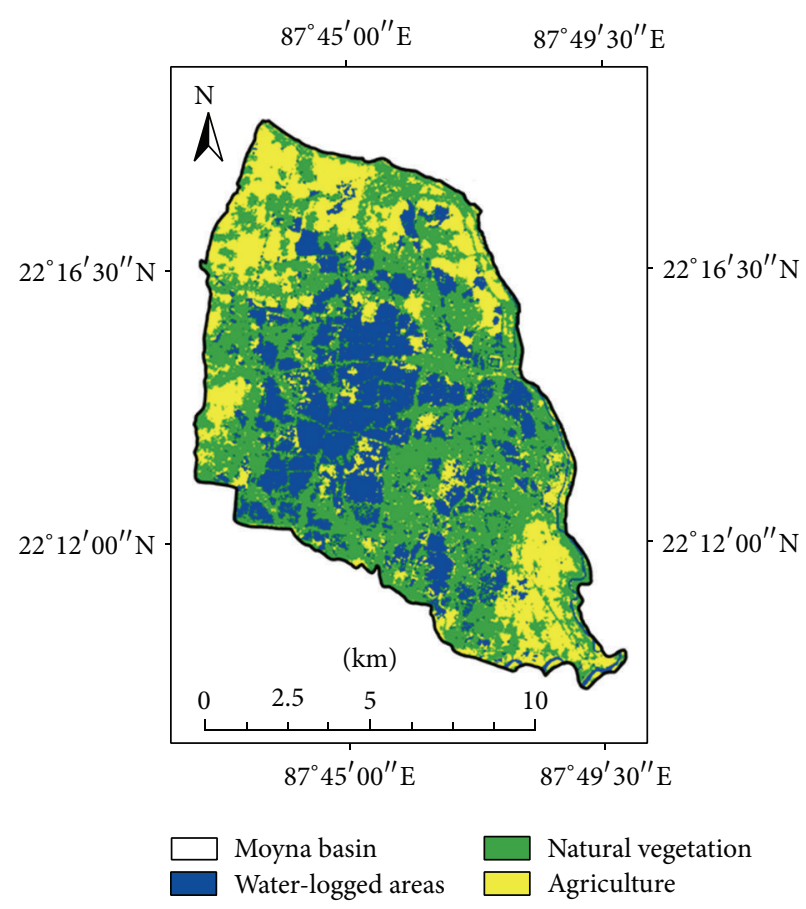

FIGURE 5: Supervised classification of USGS Landsat 5 TM bands (2009).

"management" aims to describe economic transformation controlled through spatial relations. Every year, due to heavy rainfall in the rainy season, Moyna basin experiences drainage congestion and water-logged hazard from AugustSeptember to December-January [19]. This drainage congestion and resulted standing water in the low-lying agricultural fields has negative effects on agriculture and positive on fishing activity as well. At present, paddy cultivation, specifically boro, is continuously diminishing as agricultural fields remained under water at the time of paddy cultivation for the purpose of fishing activity. Before the construction of Moyna drainage basin scheme canal in 1985-1986, on the southeast part, the study area experienced water-logged problems like failure of rice and other crop cultivations, diseases like typhoid, malaria, and so forth, transport-communication problems, among others. After the construction of this canal, since it was a general demand of local people to drain out the excess rain and/or flood water from the agricultural fields, practise of boro cultivation has increased. But from the last half of the nineteenth decade of the twentieth century, whence price of prawns continuously goes upward with other fishes also, general people transferred low-lying agricultural fields into fishing grounds feeling interest to earn much more money and for the betterment of their economic condition. Humans, taking the natural environmental support of low-lying water-logged areas, restricted lowlands to hold rainwater except its drain-out. Thus, throughout the year, areas of paddy cultivation remained captured by the fresh-water fisheries. Sahu [19] shows that almost 50 to 60 villages like Charandaschak, Baitalchak, Arong Kiarana, Ismalichak, Kripanandapur, Kiarana, Bakcha, Purba-Dakshin 
$\stackrel{N}{A}$
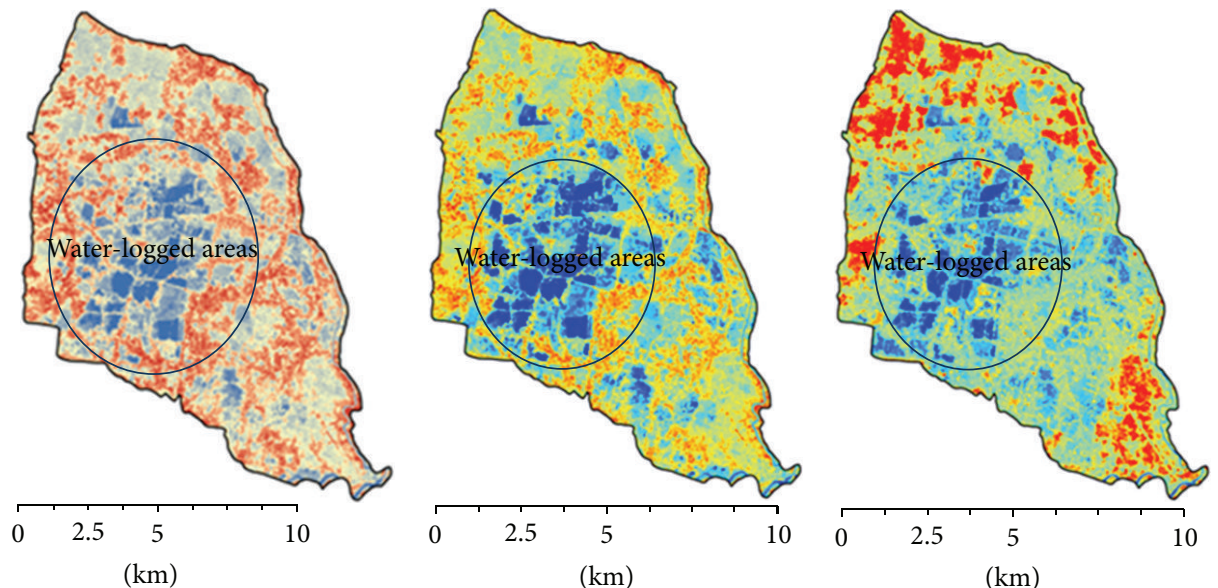

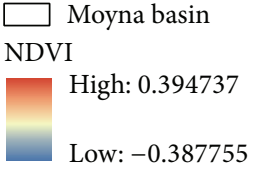

(a)

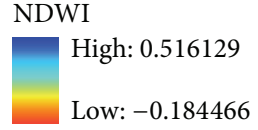

(b)

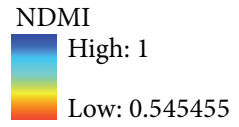

(c)

FIgURE 6: (a) NDVI; (b) NDWI; (c) modified NDWI or NDMI, based on USGS Landsat 5 TM (2009).

Moyna, Paramanandapur, and so forth, are now engaged to culture Labio rohita, Katla katla, and so forth, in their paddy fields. Galda prawns (Macrobrachium rosenbergii) in the water-logged areas of Bakcha, Arong Kiarana, Kiarana, Ismalichak, Baitalchak, Ramchak, Narikelda, and so forth, are also cultured intensively. It is obvious that prawn culture is more profitable than aus or boro paddy cultivation.

\section{Conclusion}

Water-logging is the resultant function of relationships between geological structure, soil types, surface elevation, slope, drainage density, haphazard embankments, depth of ground water, human activities, and so forth, from the spatial as well as environmental perspective. In the Moyna basin, there are many hydromorphological favourable conditions for the onset of water-logged situation. Extensive near-middle low-lying area with low relief, low and negative slope, heavy rainfall within a short span of time, favourable soil to hold water on the land surface, presence of ground water within a very short depth from the ground level, and a number of canals with haphazard embankments create water-logged condition. It is a place of water-logging, from August to November in a year, remaining surrounded by different rivers like Kasai, Chandia, and Kangsabati river. From the satellite images these water-logged areas can be identified as well as mapped using supervised classification method, NDVI, NDWI, and modified NDWI or NDMI. With the advancement of science and technology, it is experienced that humans switched off as well as modified the consequences of different problems of natural origin. It is well recognized to all that within our human society while something is hazardous to someone it is beneficiary to another. In abroad and in India also water-logging has been taken into consideration as an issue for agriculture in the rural areas due to low-lying trough like basin structure, drainage congestion, and flooding after heavy rainfall. Here, at Moyna basin, water-logging is quasinatural and seasonal in nature. Hydromorphological natures of water-logging issues and their environmental consequences are significant physically, economically, and socially also. With time, since population increases continuously with a sharp growth rate, environmentally backward areas like water-logged places are also not stepped behind to be occupied for the purposes of inhabitation and economic activity. Using different methods, aiming to change the traditional landuse pattern, people transferred waterlogged problem into economically benefitted instrument. Once, where water-logged environment was treated only as a problem for livelihood of humans today there it is helpful to earn much more money than any other agricultural practises. People of the water-logged areas transferred the physical issue of water-logging and drainage congestion into economically benefitted fishing activity.

\section{Conflict of Interests}

The author declares that there is no conflict of interests regarding the publication of this paper. 


\section{Acknowledgments}

The author acknowledges the University Grants Commission (UGC), New Delhi, India, for financial assistance. This paper is a part of study under UGC-BSR Start-Up Grant Scheme (Ref. UGC Letter no. F.20-3(17)/2012(BSR). Date: February, 2013 (March 8, 2013)) on "Environmental Consequences of Water-Logging Problem in Purba Medinipur District, West Bengal: Evaluation, Mapping, and Management.”

\section{References}

[1] B. Bowonder, K. V. Ramana, and R. Rajagopal, "Waterlogging in irrigation projects," Sadhana, vol. 9, no. 3, pp. 177-190, 1986.

[2] M. E. Bastawesy and R. R. Ali, "The use of GIS and remote sensing for the assessment of waterlogging in the dryland irrigated catchments of Farafra Oasis, Egypt," Hydrological Processes, 2012.

[3] Wikipedia, 2013, http://en.wikipedia.org/wiki/Waterlogging (agriculture).

[4] P. H. Collin, Dictionary of Environment and Ecology, vol. 223, Bloomsbury, London, UK, 2004.

[5] J. Holden, A. J. Howard, L. J. West, E. Maxfield, I. Panter, and J. Oxley, "A critical review of hydrological data collection for assessing preservation risk for urban waterlogged archaeology: a case study from the City of York, UK," Journal of Environmental Management, vol. 90, no. 11, pp. 3197-3204, 2009.

[6] A. S. Sahu, "Embankment system and sustainable development in the Moyna Flood Basin," MS Academic, vol. 2, no. 1, pp. 85-93, 2012.

[7] A. A. Kumar and P. D. Kunte, "Coastal vulnerability assessment for Chennai, East Coast of India using geospatial techniques," Natural Hazards, vol. 64, pp. 853-872, 2012.

[8] WRMIN, 2013, http://wrmin.nic.in/index3.asp?sslid=345\&subsublinkid $=354 \&$ langid $=1$.

[9] M. H. Minar, M. B. Hossain, and M. D. Shamsuddin, "Climate change and coastal zone of Bangladesh: vulnerability, resilience and adaptability," Middle-East Journal of Scientific Research, vol. 13, no. 1, pp. 114-120, 2013.

[10] F. Sheng and C. Xiuling, "Developing drainage as the basis of comprehensive control of drought, waterlogging, salinity and saline groundwater," Irrigation and Drainage, vol. 56, no. 1, pp. S227-S244, 2007.

[11] A. R. Ghumman, Y. M. Ghazaw, M. F. Niazi, and H. N. Hashmi, "Impact assessment of subsurface drainage on waterlogged and saline lands," Environmental Monitoring and Assessment, vol. 172, no. 1-4, pp. 189-197, 2011.

[12] R. Pal, "Sadhinata sangrame medinipur (1905-1947)," in Paschimbangya: Medinipur Zela Sankha, T. O. S. Bibhag, Ed., pp. 167-174, Paschimbangya Sarkar, Kolkata, India, 2004.

[13] A. Mukherjee, A. E. Fryar, and W. A. Thomas, "Geologic, geomorphic and hydrologic framework and evolution of the Bengal basin, India and Bangladesh," Journal of Asian Earth Sciences, vol. 34, no. 3, pp. 227-244, 2009.

[14] A. B. Biswas, I. Chakraborty, D. K. Das, A. Chakraborty, D. Ray, and K. Mitra, "Elimination of iodine deficiency disorderscurrent status in Purba Medinipur district of West Bengal, India," Indian Journal of Public Health, vol. 52, no. 3, pp. 130135, 2008.
[15] P. Merot, B. Ezzahar, C. Walter, and P. Aurousseau, "Mapping waterlogging of soils using digital terrain models," Hydrological Processes, vol. 9, no. 1, pp. 27-34, 1995.

[16] S. Mukhopadhyay, "Development of a Marshy area: a case study of Mayna Basin," Geographical Review of India, vol. 49, no. 3, pp. 54-59, 1987.

[17] A. I. Malik, T. D. Colmer, H. Lambers, T. L. Setter, and M. Schortemeyer, "Short-term waterlogging has long-term effects on the growth and physiology of wheat," The New Phytologist, vol. 153, no. 2, pp. 225-236, 2002.

[18] Agricoop.nic.in, 2011, http://agricoop.nic.in/Agriculture\%20 contingency\%20Plan/West $\% 20$ Bengal/WestBengal\%2015-Purba\%20Medinipur-31.12.2011.pdf.

[19] A. S. Sahu, "Embankments in relation to the physical and economic systems in the Moyna Drainage Basin," W.B. Geographical Review of India, vol. 71, no. 1, pp. 61-68, 2009.

[20] D. G. Weston, “The Influence of waterlogging and variations in pedology and ignition upon resultant susceptibilities: a series of laboratory reconstructions," Archaeological Prospection, vol. 11, no. 2, pp. 107-120, 2004.

[21] N. C. Sahu, Potassium dynamics of some soils of West Bengal in relation to clay mineralogy [Ph.D. thesis], Bidhan Chandra Krishi, Nadia, India, 1993.

[22] J. M. Bradd, W. A. Milnehome, and G. Gates, "Overview of factors leading to Dryland salinity and its potential hazard in New South Wales, Australia," Hydrogeology Journal, vol. 5, pp. 51-67, 1997.

[23] S. Basack and A. K. Bhattacharya, "Significance of hydrogeological and hydro chemical analysis in the evaluation of groundwater resources: a case study from the East Coast of India," IOSR Journal of Engineering, vol. 2, no. 9, pp. 61-71, 2012.

[24] A. Ray and S. Shekhar, "Ground water issues and development strategies in West Bengal," Bhu-Jal News, vol. 24, no. 1, pp. 1-17, 2009.

[25] NASA, Landsat 7 Science Data Users Handbook, chapter 11, NASA, 2009.

[26] A. D. Prasad, K. Jain, and A. Gairola, "Surface temperature estimation using landsat data for part of the Godavari and Tapi Basins, India: a case study," International Journal of Engineering and Advanced Technology, vol. 2, no. 3, pp. 320-322, 2013.

[27] C. J. Tucker, "Red and photographic infrared linear combinations for monitoring vegetation," Remote Sensing of Environment, vol. 8, no. 2, pp. 127-150, 1979.

[28] C. J. Tucker and B. J. Choudhury, "Satellite remote sensing of drought conditions," Remote Sensing of Environment, vol. 23, no. 2, pp. 243-251, 1987.

[29] R. D. Jackson and A. R. Huete, "Interpreting vegetation indices," Preventive Veterinary Medicine, vol. 11, no. 3-4, pp. 185-200, 1991.

[30] H. Xu, "Modification of normalised difference water index (NDWI) to enhance open water features in remotely sensed imagery," International Journal of Remote Sensing, vol. 27, no. 14, pp. 3025-3033, 2006.

[31] V. M. Chowdary, R. V. Chandran, N. Neeti et al., "Assessment of surface and sub-surface waterlogged areas in irrigation command areas of Bihar state using remote sensing and GIS," Agricultural Water Management, vol. 95, no. 7, pp. 754-766, 2008.

[32] J. Huang, D. Chen, and M. H. Cosh, "Sub-pixel reflectance unmixing in estimating vegetation water content and dry biomass of corn and soybeans cropland using normalized 
difference water index (NDWI) from satellites," International Journal of Remote Sensing, vol. 30, no. 8, pp. 2075-2104, 2009.

[33] E. H. Wilson and S. A. Sader, "Detection of forest harvest type using multiple dates of Landsat TM imagery," Remote Sensing of Environment, vol. 80, no. 3, pp. 385-396, 2002.

[34] E. P. Crist and R. C. Cicone, "A physically based transformation of Thematic Mapper data-the TM tasseled cap," IEEE Transactions on Geoscience and Remote Sensing, vol. GE-22, no. 3, pp. 256-263, 1984.

[35] A. M. Omer, "Sustainable water resources management, future demands and adaptation strategies in Sudan," Journal of Environmental Science and Water Resources, vol. 1, no. 7, pp. 151-168, 2012. 

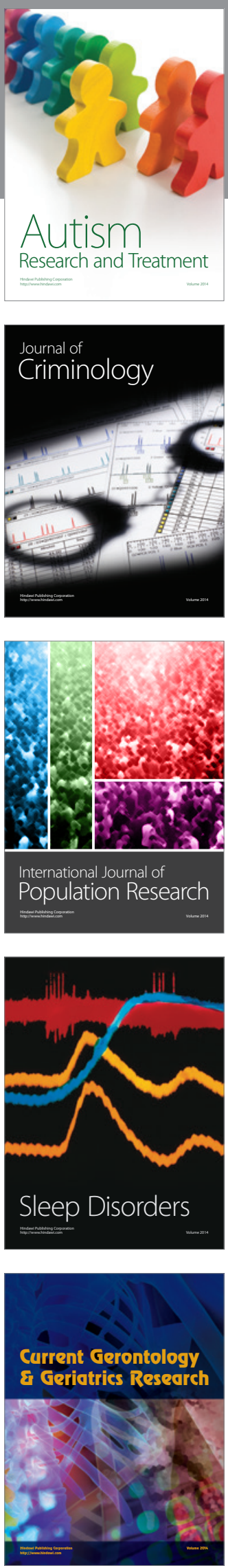
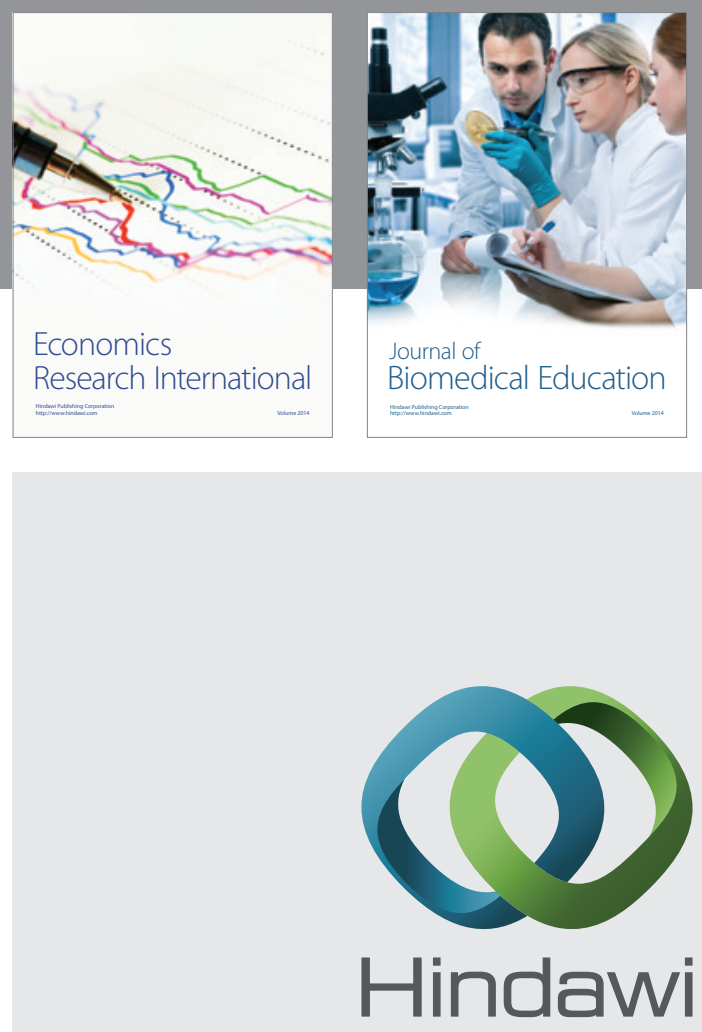

Submit your manuscripts at

http://www.hindawi.com
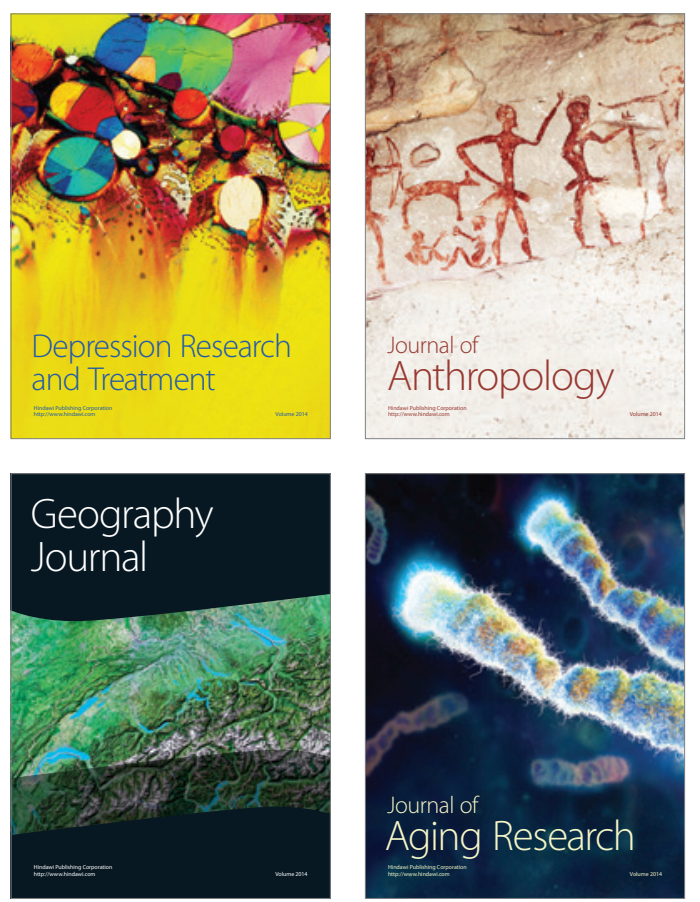
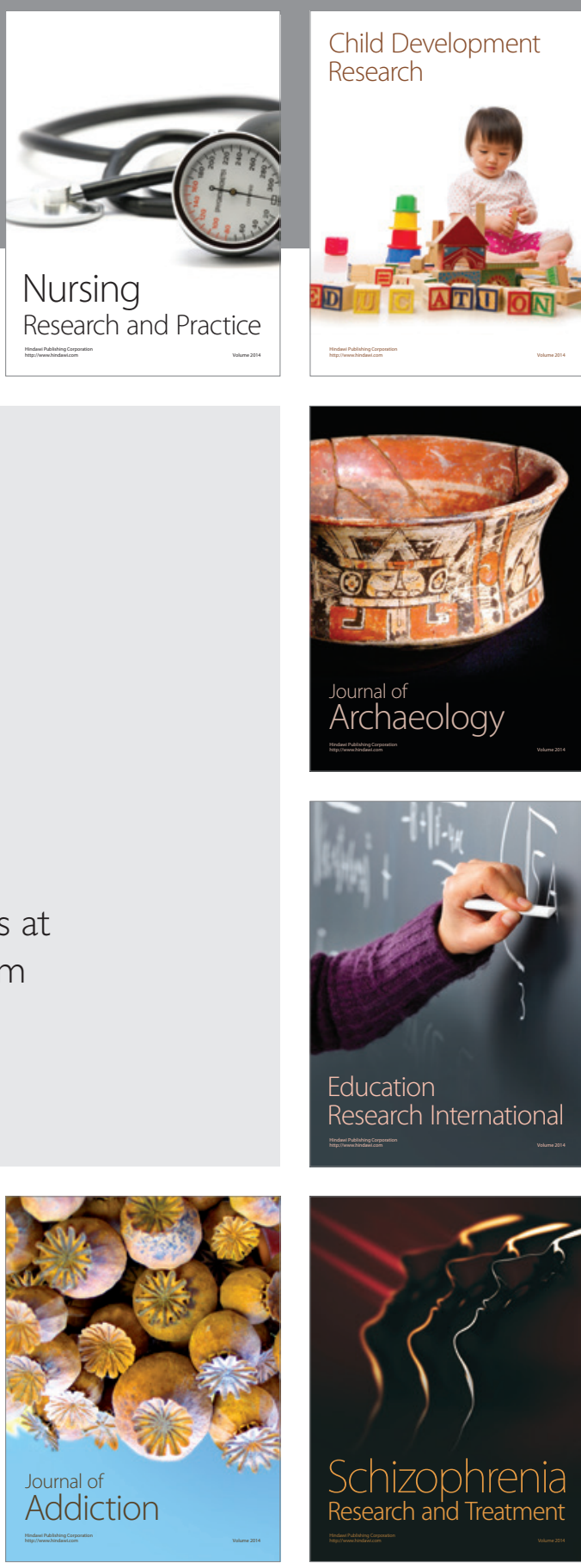

(D)
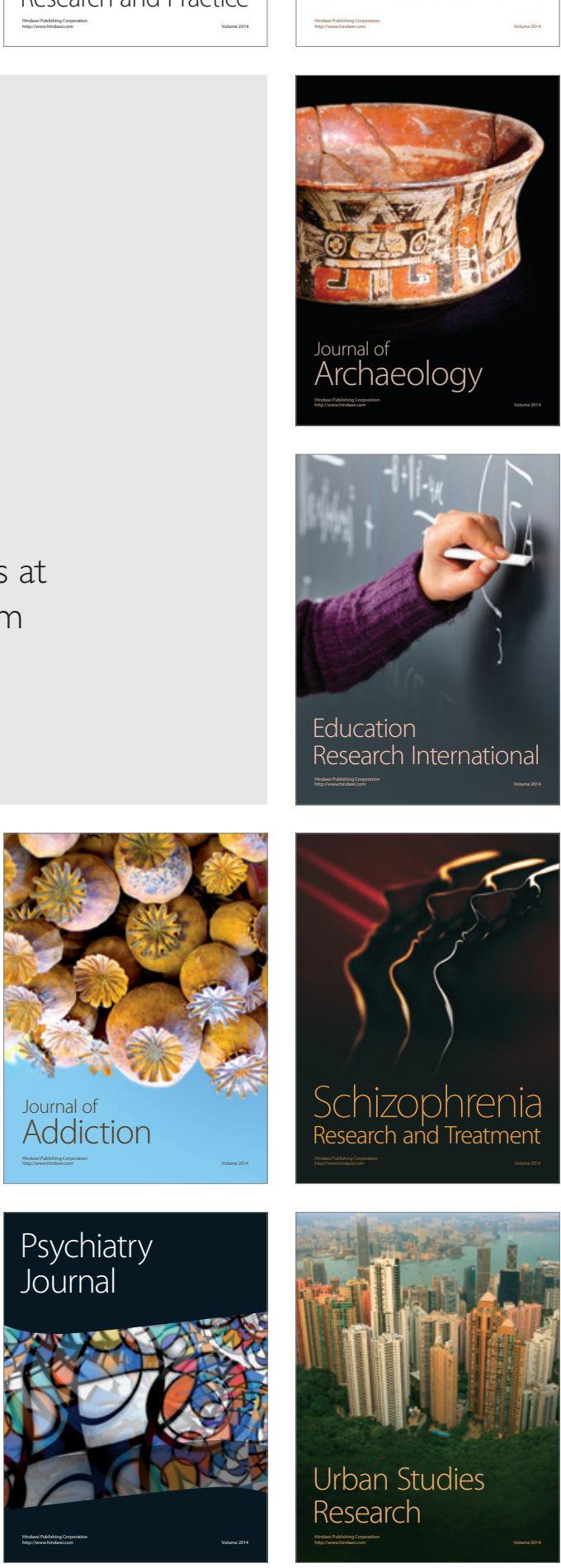